\title{
An evaluation of the implementation of a UK school-based running programme
}

Anna Chalkley ( $\square$ a.e.chalkley@lboro.ac.uk)

Loughborough University https://orcid.org/0000-0002-1163-6210

Ash C. Routen

University of Leicester Diabetes Research Centre

Jo P. Harris

Loughborough University School of Sport Exercise and Health Sciences

Lorraine A. Cale

Loughborough University School of Sport Exercise and Health Sciences

Trish Gorely

University of the Highlands and Islands

Lauren B. Sherar

Loughborough University School of Sport Exercise and Health Sciences

\section{Research}

Keywords: Physical activity, programme evaluation, implementation, school children, running

Posted Date: July 24th, 2020

DOI: https://doi.org/10.21203/rs.3.rs-45469/v1

License: () (1) This work is licensed under a Creative Commons Attribution 4.0 International License. Read Full License 


\section{Abstract \\ Background}

The adoption of school-based running programmes has rapidly increased in recent years. However, there is a lack of information on how these initiatives are implemented, and how generalisable and sustainable they are. This study evaluated the implementation of a school-based running programme, Marathon Kids (MK), over 7 months. The aim was to understand the context within which MK was implemented in each of the schools and the key elements of implementation including reach, fidelity and dose.

\section{Methods}

This study used a mixed method, single group before-and-after design strengthened by multiple interim measurements. Five state-funded primary schools in Leicestershire, UK participated, with 17 teachers and 189 (81 boys (47.4\%) and 90 girls (52.6\%)) Year 5 pupils (aged $9-10$ years) from eight classes. During the 2016/2017 academic year, data were collected via measures at multiple levels (i.e. school and individual) and at multiple time points during implementation. Follow up qualitative data were also collected during 2017/2018.

\section{Results}

Marathon Kids achieved good reach, with all pupils opting to participate at some point during the academic year. All schools implemented MK with good fidelity, although the level of implementation varied between schools and over time. The average number of MK sessions held per week ranged from $0.94-$ 3.89 with the average distance accumulated per pupil per week ranging from 0.02 to 2.91 kilometres and boys being more likely than girls to be classed as high-level participators. Despite an initial drop off in participation over time, all schools remained engaged in the programme and continued to implement MK until the end of the school year. Contextual features (e.g., staff capacity and resources) differed between schools and influenced the quality of implementation of MK and the frequency of delivery.

\section{Conclusions}

Marathon Kids is a simple, inexpensive and versatile physical activity programme which can be implemented by schools with relative at ease. However, schools are diverse settings, with unique challenges to ongoing delivery. Thus, planned adaptations, specific to each school's context, is likely necessary to sustain participation in the longer term.

\section{Contributions To The Literature}

- Research demonstrates a lack of generalisable, effective and sustainable school based physical activity interventions which have been translated into practice.

- This is the first study to systematically examine the implementation of a school-based running programme using a robust mixed method approach.

- This study contributes new evidence about how the dose (delivered and received) of a school-based physical activity programme fluctuates over time and the factors which influence its implementation.

- Although we found Marathon Kids to be implemented with good fidelity, adaptations specific to each school's context (e.g., staff capacity and resources) may increase the likelihood of positive outcomes such as sustainability.

\section{Background}

School-based running programmes (sometimes referred to as active mile initiatives) typically encourage children to be active during the school day by providing opportunities for pupils to walk and/or run around a marked route in the school grounds for a period of time (e.g., 15 minutes) (1). Grass roots support for school-based running programmes has rapidly increased in recent years (2) and many are being implemented as a pragmatic 'solution' to rising levels of childhood obesity, poor levels of fitness and inactivity (3). Indeed the most well-known example, The Daily Mile ${ }^{\text {TM }}$ (4), is reported as being implemented in over 70 countries worldwide, and over 5,867 registered schools have participated in the initiative in England alone (5).

In the United Kingdom (UK), political cross sector commitment for running programmes was reinforced by the 2019 cross-government School Sport and Physical Activity Action Plan (6), which advocated the use of active mile initiatives to establish physical activity as an integral part of the school day. However, evidence for the effectiveness of school-based interventions is mixed (7) and there are limited generalisable, effective and sustainable physical activity interventions which have been translated into practice (8). For example, a recent systematic review with meta-analysis found that school-based interventions had a moderate effect on physical activity during the school day, but this was not reflected in increases in physical activity across the whole day (9). Possible explanations are that intervention components were not effective, and/or they were not implemented appropriately. Consequently, a greater focus on documenting real-world implementation and fidelity as part of evaluations of public health interventions (10), school-based physical activity interventions (11), and school-based running programmes,(12) is needed.

Whilst intuitively running programmes are an appealing investment for schools (13), robust efficacy and implementation evidence is scarce (14). In order to maximise their potential, there is a need to understand which pupils participate in these programmes, if and how programmes can be successfully transferred 
from one context to another, and the factors which may constrain or enhance the implementation process (15). This study therefore examined the implementation of a school-based running programme over 7 months to understand the context within which MK was implemented in each of the schools, and the key elements of implementation including reach, fidelity and dose (delivered and received).

\section{Methods}

\section{Programme description}

Marathon kids (MK) is a school-based running programme managed and delivered by the charity Kids Run Free (KRF). It is described in detail elsewhere $(12,16,17)$, but in brief, MK gives primary school pupils the opportunity to walk and/or run the distance of a marathon over the school year. The programme aims to empower children of all fitness and ability levels to engage in regular physical activity. Pupils are encouraged to walk and/or run laps of a course on the school grounds once or twice a week. For every lap completed, pupils are given a lap band and the total number of bands collected per child is recorded via a digital tracking system (DTS). The DTS provides summary data regarding when pupils participate, how many laps each pupil completes and their accumulated distance and rewards are available upon reaching key milestones, for example, quarter, half, three-quarter and full marathon. Optional on-site support is also provided during a school launch event by a member of staff from KRF who, for example, delivers a marathon themed assembly, demarcates the running route(s) and helps to set up and provides training on the administration of the programme to the MK Champion (member of staff responsible for implementing MK) and a selection of MK Ambassadors (peer leaders). A summary of the programme is provided in Additional file 1 using the Template for Intervention Description and Replication in Public Health Programmes (TiDier-PHP)(18).

\section{Study design}

This study used a mixed method, single group before-and-after quasi-experimental design. This design was chosen as a pragmatic approach to exploring the implementation process and informing the development and effectiveness of implementation strategies (as opposed to the effectiveness of the intervention itself), in a way which would have relevance to practitioners and policy makers. Furthermore, it was believed to yield naturally occurring differences in types or intensities of implementation strategies, as determined by the schools and their local contexts, in order to evaluate their influence on implementation (19).

\section{Study population and recruitment}

The evaluation focused on Year 5 (9-10 years) children although schools were encouraged to implement MK in all year groups. Five schools were recruited to the study, representing a reach of $41.7 \%$. Given that the study was concerned with the organisational (school level) and individual level characteristics associated with implementation, participants from each school included the headteachers and/or deputy headteachers, Year 5 pupils/teacher(s), and the MK Champion (if this was not the Year 5 teacher). Parental consent to participate was also obtained from the pupil's parents/carers and each school provided written consent to participate in the study signed by the headteacher. All participants provided written informed consent and verbal assent prior to participation in any data collection.

\section{Data collection}

During the 2016/2017 academic year, data were collected at five timepoints (TP) over 7 months (October 2016 - June 2017) with follow-up data collected during the 2017/18 academic year at two TPs (Fig. 1). Detailed methods for the evaluation of Marathon Kids have been published in elsewhere (12). Table 1 outlines the implementation dimension assessed and the definition adopted, which was specific to MK. 
Table 1

A summary of the implementation evaluation measures used

\begin{tabular}{|c|c|c|c|c|}
\hline \multirow{2}{*}{$\begin{array}{l}\text { Implementation } \\
\text { outcome }\end{array}$} & \multirow[t]{2}{*}{ Implementation outcome definition } & \multirow[t]{2}{*}{ Description } & \multicolumn{2}{|l|}{ Data collection } \\
\hline & & & Measure & Time point \\
\hline \multirow[t]{12}{*}{ Reach } & \multirow{12}{*}{$\begin{array}{l}\text { The number (\%) of pupils and teachers involved in the } \\
\text { programme and their representativeness (e.g. by BMI, } \\
\text { SES, sex) }\end{array}$} & \multirow{5}{*}{$\begin{array}{l}\text { Organisational level: } \\
\text { Characteristics of schools } \\
\text { participating in MK }\end{array}$} & Headteacher & \multirow{12}{*}{$\begin{array}{l}\text { Pre- } \\
\text { programme }\end{array}$} \\
\hline & & & micivieva & \\
\hline & & & $\begin{array}{l}\text { Teacher } \\
\text { questionnaire }\end{array}$ & \\
\hline & & & $\begin{array}{l}\text { Pupil } \\
\text { questionnaire } \\
\text { (Q-SPACE-R) }\end{array}$ & \\
\hline & & & Observation & \\
\hline & & Individual level: & \multirow{2}{*}{$\begin{array}{l}\text { Teacher } \\
\text { questionnaire }\end{array}$} & \\
\hline & & $\begin{array}{l}\text { Characteristics of teachers/staff } \\
\text { participating in MK }\end{array}$ & & \\
\hline & & Pupil: & \multirow{2}{*}{$\begin{array}{l}\text { Participation } \\
\text { (DTS) }\end{array}$} & \\
\hline & & $\begin{array}{l}\text { Number/percentage of pupils } \\
\text { participating in MK }\end{array}$ & & \\
\hline & & \multirow[t]{3}{*}{$\begin{array}{l}\text { Characteristics of pupils } \\
\text { participating in MK }\end{array}$} & $\begin{array}{l}\text { Demographic } \\
\text { (SIMS) }\end{array}$ & \\
\hline & & & Anthropometrics & \\
\hline & & & Questionnaire & \\
\hline \multirow[t]{6}{*}{ Fidelity of delivery } & \multirow{6}{*}{$\begin{array}{l}\text { The extent to which the delivery of MK was implemented } \\
\text { as planned }\end{array}$} & Organisational level: & \multirow{3}{*}{$\begin{array}{l}\text { Teacher/MK } \\
\text { Champion } \\
\text { interview } \\
\text { Pupil focus } \\
\text { group }\end{array}$} & \multirow[t]{3}{*}{ TP2 \& TP5 } \\
\hline & & \multirow{2}{*}{$\begin{array}{l}\text { Conformity to the implementation } \\
\text { strategy i.e. use of the 'MK five } \\
\text { pillars'* }\end{array}$} & & \\
\hline & & & & \\
\hline & & \multirow{3}{*}{$\begin{array}{l}\text { Individual level: } \\
\text { Teacher, Pupil }\end{array}$} & \multirow{2}{*}{$\begin{array}{l}\text { Implementation } \\
\text { log } \\
\text { Participation } \\
\text { (DTS) }\end{array}$} & \multirow[t]{2}{*}{ Continuous } \\
\hline & & & & \\
\hline & & & Observation & $\begin{array}{l}\text { TP2, TP3, } \\
\text { TP4 }\end{array}$ \\
\hline \multirow{6}{*}{$\begin{array}{l}\text { Dose } \\
\text { delivered/received }\end{array}$} & \multirow{6}{*}{$\begin{array}{l}\text { How much of the MK sessions were delivered and } \\
\text { received }\end{array}$} & Organisational level: & \multirow{3}{*}{$\begin{array}{l}\text { Teacher/MK } \\
\text { Champion } \\
\text { interview } \\
\text { Pupil focus } \\
\text { group }\end{array}$} & \multirow[t]{3}{*}{ TP2 \& TP5 } \\
\hline & & \multirow{5}{*}{$\begin{array}{l}\text { The number of sessions/week } \\
\text { pupils participated in }\end{array}$} & & \\
\hline & & & & \\
\hline & & & $\begin{array}{l}\text { Implementation } \\
\text { log }\end{array}$ & Continuous \\
\hline & & & $\begin{array}{l}\text { Participation } \\
\text { (DTS) }\end{array}$ & \\
\hline & & & Observation & $\begin{array}{l}\text { TP2, TP3, } \\
\text { TP4 }\end{array}$ \\
\hline
\end{tabular}

\section{School level measures}

Headteacher interview

Headteachers from each of the schools participated in a semi-structured interview to elicit contextual information pertaining to their school's policies, practices and ethos relating to the promotion, teaching and delivery of physical activity and healthy lifestyles, as well as influences on the decision to adopt the programme. See Additional file 2 for an example of thematic interview/focus group guide used for the evaluation. 
Teacher questionnaire

Pre-programme, teachers responded to a series of open-ended questions about their teaching experience, qualifications and professional development relating to physical education (PE), sport, physical activity and health. In addition, teachers were asked to report their level of physical activity using a single-item physical activity measure (22).

Teacher Interviews

All Year 5 teachers and MK Champions (if different), participated in semi-structured face-to-face interviews. At TP2 and TP5, questions focused on: the characteristics of pupils and schools (participating and non-participating); the extent to which components of the intervention were used and completed; the delivery of MK and teacher satisfaction; pupil behaviour and pupil uptake and perceptions of influences on uptake. At TP6 and TP7, questions explored: the perceived long-term effects on pupils, teachers and school(s); changes to policy and practice, and any factors affecting sustainability.

Teacher log

To obtain data on the frequency and duration of exposure to MK as well as uptake, teachers were asked to complete a weekly survey (Survey Monkey, Palo Alto, California, USA) of each class' participation during the implementation period (October 2016 - June 2017). For example, data was collected on frequency, timing and duration (in minutes) of use of MK during the week as well as contextual information such as surface/route used and supervision.

\section{Pupil}

Demographics

At TP1, each pupil's name, date of birth, sex, ethnicity, free school meal eligibility (eFSM) and home postcode were collected from the school information management system. Relative deprivation and area-level socioeconomic status was calculated based on home postcode using the 2015 English Index of Multiple Deprivation (IMD) (20). Home postcodes were uploaded to an online 'postcode lookup' tool[1], which outputted the corresponding IMD rank and decile.

\section{Anthropometrics}

Each pupils' standing height and weight was measured and body mass Index calculated (23) pre (beginning of the school year) and post-programme (end of the school year).

Physical activity

Physical activity data were collected pre- and post-programme with a waist worn ActiGraph triaxial accelerometer (GT3X, GT3X+ or BT) (ActiGraph, Pensacola, FL, USA). Participants were instructed to wear the device on their right hip during all waking hours, except when engaging in water-based activities, for seven consecutive days.

Pupil focus groups

Semi-structured focus groups were conducted with pupils at TP2 and TP5. Focus groups were chosen to provide rich data relating to pupils' perceptions of MK, facilitate a detailed description of the implementation of MK, and understand how those perspectives may be different from, or similar to, their peers' as well as their teachers'. One mixed sex group of six to eight year 5 pupils per class participated $(n=53$ in total) and were selected by the MK Champions based on the following guidelines: ensuring a range of pupils in relation to, sex, enthusiasm and participation level in the programme (e.g., high, medium and low), as well as their willingness to communicate experiences and opinions.

\section{Running programme participation}

At TP2, TP3 and TP4, pupils' participation in MK during a lunchtime period was assessed using direct observation. Data collected during these structured observations were largely qualitative and involved the researcher making detailed notes of relevant contextual and other information (e.g., weather, route used, duration of the session, level and type of interactions observed (i.e., physical or verbal and prosocial or antisocial interaction), fidelity to the MK protocol, and approximate numbers of pupils participating).Participation in MK was ascertained via triangulating data from the DTS, direct observations and the implementation log completed by teachers Specifically, data from the DTS were verified using contextual information from the teacher implementation log to determine the dose (i.e., distance covered) for each child pupil over time.

\section{Data analyses}

\section{Qualitative data}

All qualitative data were deductively coded, using a Framework approach to thematic analysis (24), into a priori themes based on the implementation outcomes of interest (i.e. reach, fidelity, dose). The Framework approach was chosen to help link data from different sources within the study and map the dynamics of implementation over time enabling comparisons between, and associations within, cases to be identified systematically (25). 


\section{Quantitative data}

Descriptive statistics, expressed as mean and standard deviation (SD) or percentages, were employed to explore the school, teacher and pupil level characteristics, as well as level of implementation (obtained from teacher logs and DTS) over time and between schools.

\section{Results}

Overall, five schools, 17 teachers, and 189 pupils from eight classes were recruited to the study. The final sample consisted of 16 teachers and 171 pupils ( 81 boys (47.4\%) and 90 girls (52.6\%)).

The schools ranged in denomination, size, location, deprivation (IDACl and eFSM) and performance (Ofsted rating). Schools 2 and 4 were federated (i.e., with one single overarching governing body accountable for both). The characteristics of each school are summarised in Table 2.

Table 2

Summary of school characteristics

\begin{tabular}{|c|c|c|c|c|c|c|}
\hline School & $\begin{array}{l}\text { Urban/Rural } \\
\text { description }\end{array}$ & Status & $\begin{array}{l}\text { No of pupils in the } \\
\text { school }\end{array}$ & Ofsted rating & $\begin{array}{l}\text { IDACl } \\
\text { (declie) }\end{array}$ & $\begin{array}{l}\text { eFSM } \\
(\%)\end{array}$ \\
\hline 1 & Urban & Community school & 186 & Good & 9 & 34.9 \\
\hline 2 & Rural village & $\begin{array}{l}\text { Church of England Academy } \\
\text { converter }\end{array}$ & 58 & Good & 10 & 11.8 \\
\hline 3 & Rural town and fringe & Church of England & 501 & Outstanding & 6 & 16.4 \\
\hline 4 & Rural town and fringe & $\begin{array}{l}\text { Church of England Academy } \\
\text { converter }\end{array}$ & 215 & Good & 4 & 24.7 \\
\hline 5 & Urban & Academy sponsor led & 355 & $\begin{array}{l}\text { Requires } \\
\text { improvement }\end{array}$ & 5 & 18.8 \\
\hline
\end{tabular}

Five head/deputy heads, two teachers and one teaching assistant were recruited for the interviews/focus groups. Of the recruited teachers, five adopted the role of MK Champions, three of whom were male, with an average of $10.2 \pm 6.3$ years of teaching experience, ( $4 \pm 2.1$ years in their current school).

The majority (73.9\%) were White British and $26.1 \%$ of participants were classified as overweight or obese (Table 3). On average pupils spent 58.9 ( \pm 23.1 ) minutes per day in moderate to vigorous physical activity (MVPA) with 38.8\% meeting the UK Chief Medical Officer's physical activity guidelines (26). 
Table 3

Individual level characteristics of pupils participating in Marathon Kids

\begin{tabular}{|c|c|c|c|}
\hline Variable & $\begin{array}{l}\text { Male } \\
(n=81 ; 47.4 \%)\end{array}$ & $\begin{array}{l}\text { Female } \\
(n=90 ; 52.6 \%)\end{array}$ & $\begin{array}{l}\text { Total } \\
(n=171)\end{array}$ \\
\hline Age & $9.6 \pm 0.4$ & $9.7 \pm 0.3$ & $9.7 \pm 0.3$ \\
\hline \multicolumn{4}{|l|}{ Ethnicity } \\
\hline White British & $52(64.2 \%)$ & $53(58.9 \%)$ & $105(73.9 \%)$ \\
\hline Asian (South Asian and East Asian) & $3(3.7 \%)$ & $3(3.3 \%)$ & $6(3.5 \%)$ \\
\hline Other & $14(17.3 \%)$ & $19(21.1 \%)$ & $33(19.3 \%)$ \\
\hline eFSM, & $11(13.6 \%)$ & $10(11.1 \%)$ & $21(12.3 \%)$ \\
\hline IMD decile score & $7.14( \pm 2.7)$ & $6.41( \pm 2.8)$ & $6.77( \pm 2.6)$ \\
\hline Overweight and obese & $25(30.5 \%)$ & $24(24.5 \%)$ & $49(26.1 \%)$ \\
\hline \multicolumn{4}{|l|}{ Accelerometer variables } \\
\hline Monitor wear (minutes/day) & $721.4( \pm 83.2)$ & $704.6( \pm 83.2)$ & $724.3( \pm 71.5)$ \\
\hline School day* monitor wear (minutes/day) & $267.32( \pm 122.7)$ & $221.5( \pm 114.3)$ & $306.6( \pm 104.8)$ \\
\hline Sedentary (minutes/day) & $411.6( \pm 67.6)$ & $420.9( \pm 71.3)$ & $416.83( \pm 69.6)$ \\
\hline Light (minutes/day) & $239.2( \pm 39.9)$ & $229.6( \pm 44.5)$ & $233.84( \pm 42.7)$ \\
\hline MVPA (minutes/day) & $68.1( \pm 24.6)$ & $51.6( \pm 18.9)$ & $58.9( \pm 23.1)$ \\
\hline Pupils achieving $\geq 60$ minutes of MVPA on every valid day & $35(23.8 \%)$ & $22(14.9 \%)$ & $57(38.8 \%)$ \\
\hline Pupils achieving $\geq 30$ minutes of MVPA on every valid school day & $16(76.2 \%)$ & $5(23.8 \%)$ & $21(24.4 \%)$ \\
\hline \multicolumn{4}{|c|}{$\begin{array}{l}\text { IMD } 2015 \text { decile scores range from } 1 \text { to } 10 ; 1 \text { is the least deprived and } 10 \text { is the most deprived. Note, Ethnicity is based on } 142 \text { participants, Weight statu } \\
\text { based on } 153 \text { participants, IMD data based on } 142 \text { participants, eFSM based on } 140 \text { participants, standing height based on } 156 \text { participants, } \\
\text { accelerometer data based on } 96.7 \% \text { of participants providing valid data. Pupils achieving } \geq 30 \text { minutes of MVPA on every valid school day based on } \\
56.6 \% \text { of participants providing valid data to examine school-based physical activity. }\end{array}$} \\
\hline \multicolumn{4}{|c|}{$\begin{array}{l}\text { (Values given are means and standard deviations unless otherwise stated, eFSM = Free school meal eligibility, MVPA = Moderate to vigorous physical } \\
\text { activity, IMD = Index of Multiple Deprivation, * School day was defined as } 08.30-15.00)\end{array}$} \\
\hline
\end{tabular}

The duration of the focus groups ranged between 28-63 minutes (average 42.5 minutes) and the interviews lasted between 12-43 minutes (average 23.4 minutes).

\section{School implementation context}

The dominant reasons for headteachers adopting MK was the perception that it offered something new and different and/or that it complemented and aligned with other initiatives and policies, and it was accessible to all pupils.

That was one of the draws for us really because some projects don't work because they don't work with the different ethnic groups or because it's something that is very language driven, but for this any child can join in without needing to have it explained to them other than follow that person because they are now running and so are you. Headteacher, School 5 (Pre-programme)

Of the five schools, two (School 1 and 2) implemented MK across all year groups; Schools 3 and 4 implemented it with Key Stage 2 only (7-11 years), and School 5 implemented it with all year groups apart from Reception (4-5 years). Schools experienced various challenges and to varying degrees, relating for example, to staffing and poor facilities and infrastructure, when planning to implement MK. Every school offered MK as a lunchtime activity, which provided additional benefits.

We are a school that has always had activities to do because lunchtime is when you have the most incidents, so we do have structured activities most lunchtimes for everybody anyway, that does help. MK Champion, School 4 (TP5)

School 3 also delivered MK at other times including before school, during PE, at lunchtime and after school. The MK Ambassadors oversaw delivery in Schools 1 and 5, whereas the lunchtime supervisors and the MK Champion took responsibility for delivery in Schools 2 and 4 and in School 3 , respectively.

All schools delivered MK throughout the entire academic year although the number of weeks of delivery varied according to the different start time points (10th October to 28th November). Consequently, the minimum distance per week to complete a marathon ranged from $1.51 \mathrm{~km}$ (School 1 ) to $2 \mathrm{~km}$ (School 3 ). The length of the pre-marked route ranged from $70.2 \mathrm{~m}$ (School 2) to $124.5 \mathrm{~m}$ (School 5) and the dominant surface used for MK across all schools was tarmac, with Schools 4 and 5 using this for $100 \%$ of sessions. Three of the schools (School 1, 2 and 4 ) using existing markings on the playground. School 3 used the perimeter of a teaching block, while School 5's route partly followed the outline of the trim trail on their playground. 


\section{Reach}

Marathon Kids reached all pupils in Year 5 from all schools at some point during the academic year, although the dose of MK fluctuated. The qualitative data showed that there was a perception among staff that pupils who continued to participate were those who were characteristically competitive and responded positively to challenges (such as completing a marathon). In some schools these were the more active and 'sporty' children, but two of the five MK Champions commented on their surprise at several children participating who did not usually join in optional physical activity at school. This suggests that the programme appealed to an array of children, and not just the already active.

Just looking purely from my class, yes, it's those that are always engaged, always enthusiastic or always try their best whatever you throw at them, they're the ones who tend to do it. But coupled with that you've got those who, shall we say, the less sporty inclined so those who don't necessarily take part because it's too much effort. Year 5 teacher, School 5 (TP2)

\section{Fidelity}

To determine the extent to which MK was implemented as intended, the schools' delivery of MK was assessed against the core principles of the programme. In accordance with an approach previously used in school based physical activity interventions (27), fidelity markers were either coded as not employed at all (0), partially employed (1), or fully employed (2), based on data from the DTS, observations, implementation log and interviews and focus groups. The fidelity scores are summarised in Table 4. Whilst all schools scored similarly for fidelity to MK, variation by marker of fidelity was evident. Schools scored the lowest on adhering to the reward-based strategy and issuing rewards at key milestones.

Table 4

Summary of the assessment of schools' fidelity to Marathon Kids (MK)

\begin{tabular}{|c|c|c|c|c|c|c|c|}
\hline $\begin{array}{l}\text { MK implementation } \\
\text { strategy }\end{array}$ & Fidelity markers & $\begin{array}{l}\text { School } \\
1\end{array}$ & $\begin{array}{l}\text { School } \\
2\end{array}$ & $\begin{array}{l}\text { School } \\
3\end{array}$ & $\begin{array}{l}\text { School } \\
4\end{array}$ & $\begin{array}{l}\text { School } \\
5\end{array}$ & $\begin{array}{l}\text { Fidelity marker } \\
\text { total }\end{array}$ \\
\hline Celebration & A launch event is held & 2 & 2 & 2 & 2 & 2 & 10 \\
\hline Role modelling & MK Champion and MK Ambassadors identified & 2 & 2 & 2 & 2 & 2 & 10 \\
\hline Goal setting & $\begin{array}{l}\text { Opportunity for pupils to participate once to twice } \\
\text { a week }\end{array}$ & 2 & 2 & 2 & 2 & 2 & 10 \\
\hline \multirow[t]{3}{*}{ Monitoring/ tracking } & Takes place along an identified marked route & 2 & 2 & 1 & 2 & 1 & 8 \\
\hline & Lap bands are used to monitor laps completed & 2 & 2 & 1 & 2 & 2 & 9 \\
\hline & DTS used to track progress & 2 & 2 & 2 & 2 & 2 & 10 \\
\hline \multirow[t]{2}{*}{ Reward } & Rewards issued at key milestones & 1 & 1 & 2 & 1 & 1 & 6 \\
\hline & & & & & & & 63 \\
\hline \multirow[t]{2}{*}{ School total: } & & 13 & 13 & 12 & 13 & 12 & \\
\hline & & $(81.3 \%)$ & $(81.3 \%)$ & $(75 \%)$ & $(81.3 \%)$ & $(75 \%)$ & \\
\hline
\end{tabular}

\section{Adaptation}

Planned adaptations in implementation related to the issuing of rewards and certificates, and to the logging of laps, both of which were recorded as having partial fidelity. Two MK Champions (School 1 and 2) created their own certificates considering these to be more personalised, and/or to better reflect the wider values of MK such as rewarding perseverance (e.g. most consistent runner) rather than just distance. In addition, School 5's MK Champion decided to award certificates and stickers to pupils who were 'close enough', to spur them on.

Because the stickers they produce are big and they are quite nice and stuff so I think that might have an impact; if they see a child walking around with a $10 \mathrm{k}$ sticker, that might get some other people interested. But if you haven't done Marathon Kids for several weeks, $10 \mathrm{k}$ is just so out of range for them that will be difficult. MK Champion, School 5 (TP2)

Lap bands were used in all schools to record the number of laps run during a MK session; however, for pragmatic reasons, School 3 did not adopt these when implementing MK during PE to save time. Instead, each pupil was given a minimum of five laps and pupils were asked to report if they completed more than this.

\section{Dose of MK delivered}

There was good compliance $(87.6 \% \pm 6.5 \%)$ by the MK Champions in completing the online implementation log, with one school (School 2$)$ completing $100 \%$ of the logs. School 4 reported the highest number of sessions per week (3.9 \pm 2.5$)$ and School 5 the least (0.9 \pm 0.7$)$ (Table 5). The average duration of a MK 
session varied between schools with the shortest sessions ( $0-5$ minutes) being when it was used as a warm-up before PE, and the longer sessions ( $>30$ minutes) taking place during lunchtime. This was corroborated by the lunchtime observations.

Table 5

Dose of Marathon Kids (MK) delivered (based on teacher implementation log data)

\begin{tabular}{|c|c|c|c|c|c|c|c|c|c|c|c|}
\hline \multirow[t]{2}{*}{ School } & \multirow[t]{2}{*}{ Class } & \multirow{2}{*}{$\begin{array}{l}\begin{array}{l}\text { No of weeks of } \\
\text { implementation }\end{array} \\
\begin{array}{l}\text { (From launch date to } \\
\text { close of programme, } \\
\text { minus holidays) }\end{array}\end{array}$} & \multirow{2}{*}{$\begin{array}{l}\text { No of weeks } \\
\text { of completed } \\
\text { log data }\end{array}$} & \multirow{2}{*}{$\begin{array}{l}\text { No of weeks of } \\
\text { delivery }\end{array}$} & \multirow{2}{*}{$\begin{array}{l}\text { No of } \\
\text { sessions } \\
\text { of MK } \\
\text { offered }\end{array}$} & \multicolumn{6}{|c|}{ Average duration of MK session per week* } \\
\hline & & & & & & $\begin{array}{l}0-5 \\
\text { mins }\end{array}$ & $\begin{array}{l}5- \\
10 \mathrm{~min}\end{array}$ & $\begin{array}{l}10- \\
15 \text { min }\end{array}$ & $\begin{array}{l}15- \\
20 \text { min }\end{array}$ & $\begin{array}{l}20- \\
30 \text { min }\end{array}$ & $\begin{array}{l}\text { More } \\
\text { than } \\
30 \mathrm{~min}\end{array}$ \\
\hline $\begin{array}{l}\text { School } \\
1\end{array}$ & & 28 & $23(82 \%)$ & $19(83 \%)$ & 33 & 0 & 0 & 0 & 0 & $6.1 \%$ & $93.9 \%$ \\
\hline $\begin{array}{l}\text { School } \\
2\end{array}$ & & 24 & $24(100 \%)$ & $23(96 \%)$ & 45 & 0 & 0 & 0 & $36.6 \%$ & $2.9 \%$ & 0 \\
\hline \multirow[t]{3}{*}{$\begin{array}{l}\text { School } \\
3\end{array}$} & $\begin{array}{l}\text { Class } \\
\text { A }\end{array}$ & 21 & $19(86 \%)$ & $15(79 \%)$ & 28 & $3.6 \%$ & $10.7 \%$ & $28.6 \%$ & $46.4 \%$ & $10.7 \%$ & 0 \\
\hline & $\begin{array}{l}\text { Class } \\
\text { B }\end{array}$ & 21 & $19(86 \%)$ & $15(79 \%)$ & 29 & $3.4 \%$ & $10.3 \%$ & $20.7 \%$ & $13.3 \%$ & $2.9 \%$ & 0 \\
\hline & $\begin{array}{l}\text { Class } \\
\mathrm{C}\end{array}$ & 21 & $19(86 \%)$ & $15(79 \%)$ & 28 & $3.6 \%$ & $10.7 \%$ & $21.4 \%$ & $55.2 \%$ & $10.4 \%$ & 0 \\
\hline $\begin{array}{l}\text { School } \\
4\end{array}$ & & 23 & 20 (87\%) & $18(94.7 \%)$ & 70 & 0 & 0 & $10 \%$ & $21.7 \%$ & $14.7 \%$ & 0 \\
\hline \multirow[t]{2}{*}{$\begin{array}{l}\text { School } \\
5\end{array}$} & $\begin{array}{l}\text { Class } \\
\text { A }\end{array}$ & 25 & $20(80 \%)$ & 16 (84\%) & 15 & $5.9 \%$ & 0 & 0 & $1.7 \%$ & $35.4 \%$ & $11.1 \%$ \\
\hline & $\begin{array}{l}\text { Class } \\
\text { B }\end{array}$ & 25 & 20 (80\%) & 16 (84\%) & 15 & $5.9 \%$ & 0 & 0 & $1.7 \%$ & $35.4 \%$ & $11.1 \%$ \\
\hline Range & & $29-33$ & $19-24$ & $16-23$ & $15-70$ & $0-1$ & $0-3$ & $0-8$ & $0-49$ & $1-18$ & $0-31$ \\
\hline Mean & & 29 & 21.2 & 18.2 & 32.9 & & & & & & \\
\hline
\end{tabular}

\section{Dose of MK received}

In all schools, a decline in the distance covered was seen after the first week of implementation; however, thereafter the average distance remained fairly stable. Table 6 summarises the dose of MK received by pupils based on the data obtained from the DTS. The average distance accumulated per child per week ranged from $0.02 \mathrm{~km}$ to $2.91 \mathrm{~km}$. The greatest average distance per child per week was observed in School 2 with $1.34 \mathrm{~km}$, and the least in School 5 (Class B) at $0.47 \mathrm{~km}$.

Pupils were classed as being either low, medium or high with regards to participation using the interquartile ranges of the average distance walked and/or ran per week per pupil, taken from the DTS. Across all schools, boys were more likely than girls to be classed as high participating (44\% vs $12 \%)$. Differences within classes of the same school were also apparent, particularly in School 3 where the average distance per child per week ranged from 0.73 to 2.91 . Children in School 1 achieved the furthest total distance of $597.6 \mathrm{~km}$ closely followed by children in School 3 . School 3 also had the two highest performing classes in terms of average distance per pupil and the most pupils to have completed a marathon. Meanwhile School 2, had the greatest average distance per participant of $32.28 \mathrm{~km}$ with $100 \%$ of participants having completed a half marathon or more.

The qualitative data support the DTS data with overall participation ebbing and flowing as initial interest and enthusiasm for MK waned before finding 'its natural level'. At the outset some MK Champions reported a mixed response among pupils with some very enthusiastic and others less so, but across all schools initial high participation in MK was followed by a gradual decline.

It started off the first couple of weeks with big mobs of children running; very very keen and enthusiastic. The assembly did enthuse them and that went really well, and then gradually as weeks have gone on numbers have gone down and down to the sort of current point where we maybe have sort of ten running at a lunchtime. MK Champion, School 5 (TP2)

There was also an expectation among school staff at the outset that MK may not have the same appeal and longevity for all pupils; however, they felt that this was typical with many initiatives introduced into school, particularly when pupils self-select to participate. Interestingly, MK Champions frequently commented on how they thought MK was more effective for particular year groups. For example, in School 1, Year 3 had the highest participation rate whereas in School 2, Year 4 were the most committed participators. 
Dose of Marathon Kids (MK) received (based on Digital Tracking System data)

\begin{tabular}{|c|c|c|c|c|c|c|c|c|c|c|c|}
\hline \multirow[t]{3}{*}{ School } & \multirow[t]{3}{*}{ Class } & \multicolumn{10}{|c|}{ Dose of MK received } \\
\hline & & \multirow[t]{2}{*}{$\begin{array}{l}\text { Total distance } \\
(\mathrm{Km})\end{array}$} & \multirow[t]{2}{*}{$\begin{array}{l}\text { Average distance per } \\
\text { pupil }(\mathrm{Km})\end{array}$} & \multicolumn{2}{|c|}{$\begin{array}{l}\text { Average distance per pupil per } \\
\text { week }(\mathrm{Km})\end{array}$} & \multicolumn{3}{|c|}{ Boys (\%) } & \multicolumn{3}{|c|}{ Girls (\%) } \\
\hline & & & & & Min-max & Low & Medium & High & Low & Medium & High \\
\hline $\begin{array}{l}\text { School } \\
1\end{array}$ & & 597.6 & 21.3 & 0.76 & $0.14-1.7$ & 25 & 25 & 50 & 25 & 58.3 & 16.7 \\
\hline $\begin{array}{l}\text { School } \\
2\end{array}$ & & 258.2 & 32.3 & 1.34 & $0.92-1.8$ & 50 & 0 & 50 & 16.7 & 66.7 & 16.7 \\
\hline \multirow[t]{3}{*}{$\begin{array}{l}\text { School } \\
3\end{array}$} & $\begin{array}{l}\text { Class } \\
\text { A }\end{array}$ & 724.0 & 27.8 & 1.33 & $0.73-2.9$ & 25 & 25 & 50 & 61.5 & 30.8 & 7.7 \\
\hline & $\begin{array}{l}\text { Class } \\
\mathrm{B}\end{array}$ & 447.1 & 26.3 & 1.25 & $0.81-1.8$ & 20 & 30 & 50 & 0 & 66.7 & 33.3 \\
\hline & $\begin{array}{l}\text { Class } \\
\mathrm{C}\end{array}$ & 602.7 & 23.2 & 1.10 & $0.80-1.6$ & 0 & 66.6 & 33.3 & 17.6 & 82.4 & 0 \\
\hline $\begin{array}{l}\text { School } \\
4\end{array}$ & & 419.8 & 16.8 & 0.76 & $0.20-1.3$ & 0 & 50 & 50 & 30.8 & 61.5 & 7.7 \\
\hline \multirow[t]{2}{*}{$\begin{array}{l}\text { School } \\
5\end{array}$} & $\begin{array}{l}\text { Class } \\
\text { A }\end{array}$ & 448 & 20.4 & 0.81 & $0.02-1.9$ & 28.6 & 21.4 & 50 & 12.5 & 50 & 37.5 \\
\hline & $\begin{array}{l}\text { Class } \\
\text { B }\end{array}$ & 247.4 & 11.8 & 0.47 & $0.02-0.9$ & 11.1 & 77.8 & 11.1 & 40 & 60 & 0 \\
\hline $\begin{array}{l}\text { Total } \\
\text { (n) }\end{array}$ & & & & & & 15 & 28 & 34 & 24 & 51 & 10 \\
\hline $\begin{array}{l}\text { Total } \\
(\%)\end{array}$ & & & & & & 19.5 & 36.4 & 44.1 & 28.2 & 60 & 11.8 \\
\hline
\end{tabular}

\section{Level of implementation}

Schools were categorised as being high, medium or low implementers based on a combination of the interquartile range of dose of MK delivered, and fidelity of delivery (see Table 7). One school was classified as having a low level of implementation (School 5), three as medium (Schools 1, 2 and 3), and one as having a high level of implementation (School 4).

Table 7

Summary of the level of implementation of Marathon Kids (MK)

\begin{tabular}{|llll|}
\hline School & Dose of MK delivered & Fidelity of delivery to MK (\%) & Level of implementation of MK \\
\hline School 1 & Medium & 81.25 & Medium \\
\hline School 2 & Medium & 81.25 & Medium \\
\hline School 3 & Medium & 75 & Medium \\
\hline School 4 & High & 81.25 & High \\
\hline School 5 & Low & 75 & Low \\
\hline
\end{tabular}

\section{Quality of Implementation}

The quality of delivery of MK by teachers was assessed via interviews with school staff, focus groups with pupils, and observations. Several themes were identified. Staff capacity and staff buy-in were felt to be the most important determinants of how well MK had been implemented and drove many of the decisions regarding delivery. Noticeably, the role of the MK Champion within each school was thought by some to be a significant factor relating to the effectiveness of the programme's implementation. This was not only in terms of their ability to engage pupils and encourage participation but also in terms of ensuring MK was manageable and 'working for the school'. This was contextualised to the school, although there was an agreement from all that the role of the MK Champion was an essential element of the programme.

I think the programme needs someone who, someone in charge really because it would fall apart. MK Champion, School 1 (TP6) 
For example, the MK Champion in School 1 was chosen for the role because it complimented her other responsibilities within the school, (i.e., as lead for healthy schools). In School 2, the deputy headteacher felt that her strategic role within the senior management team helped to gain staff buy-in and ensure that "Marathon Kids became part and parcel of what we do as a school". The influence of the MK Champion was most evident in School 3 given the synergy between the nature and ethos of the programme and his responsibility as PE lead, and in schools 4 and 5 by the absence of a MK Champion as a figurehead for the programme.

All teachers approved of their schools' participation in MK and were supportive of pupils taking part, agreeing that the anticipated health benefits were important and valued. However, all MK Champions and many teachers discussed lack of time as a limiting factor to the degree to which they and other members of staff had been able to engage with the programme.

Teachers are very busy people and lunchtimes in particular are very busy. You're trying to have your lunch first of all and then set up for the afternoon lessons. That's what lunch hours tend to be so there was limited opportunity for us to go out there. MK Champion, School 5 (TP5)

Many pupils highlighted a lack of support from class teachers particularly as time progressed (e.g., in praising their participation and/or providing feedback on their progress). Some teachers, however, were active role models and firm advocates for the programme. Most notably, this was seen in School 1 where both the headteacher and MK Champion participated alongside the pupils. Indeed, in this school staff participation in MK was highlighted by all pupils as being an enjoyable element of the programme and provided a rare opportunity to chat informally with the headteacher. It was also evident during the observations that the headteacher's participation in MK was influential in setting a level of expectation for the school and establishing participation in the programme as the norm.

We have some staff members who were 'well why are we doing that for all the classes?'. I don't have many negative nellies, I'm hoping that because I'm going to go out there and do it, and [MK Champion] has said that she wants to, I'm hoping that we can bring them along with the tide. Headteacher, School 1 (Preprogramme)

In Schools 1, 3 and 5, delivery was predominantly facilitated by the MK pupil Ambassadors with varying degrees of support from the MK Champions and/or other members of staff. This was an efficient method of delivery in School 1, with the introduction of a rota system leading to a structured and organised running of the programme. However, other schools relied almost entirely on the MK Ambassador input due to limited school capacity to organise and champion the programme and at a detriment to the quality of the programme.

For all schools, the timing of MK was determined by logistical influences such as the capacity to supervise and manage the delivery of MK. School 4's high level of implementation of MK was partly attributed to the fact that lunchtime supervisors coordinated delivery. Indeed, when observed, the MK sessions appeared to be an organised and consistent part of the school's lunchtime routine.

Most of the time now you don't even know you're doing it because you automatically just do it and you don't know that you are just doing it yourself. Year 5 boy, School 4 (TP5)

School 2 (federated with School 4), used the same approach to delivering MK where the MK Champion also frequently referred to the programme as becoming 'routine' and part of the 'status quo'. However, participation in MK was equally perceived by many pupils from both schools as a compulsory activity whereby they were required to achieve a minimum number of laps before being 'allowed' to play, and indeed the lunchtime supervisors were often observed providing instructions to pupils in an authoritarian manner rather than encouragement. While this style of implementation may have contributed to the high dose of MK, it may have been at the expense of pupils' sense of enjoyment and autonomy of the activity, as one pupil stated: "Sometimes it's a bit of a torture because you just want to play." Year 5 boy, School 2 (TP5).

Conversely, in School 5, roles and responsibilities for delivering MK were not so clearly defined. Consequently, frequent disagreements were observed among the MK Ambassadors and between the MK Ambassadors and other pupils in the playground leading to disruption in delivery. In this school, pupils felt that adult support was needed to deliver MK, specifically to help protect the integrity of the monitoring system (i.e., the perception that pupils lacked authority to deal with cheating and disruptive behaviour). In hindsight, teachers also reflected on this challenge.

Yeah in all honesty I didn't have the time to run it properly. What it really needed is a member of staff out there in a tracksuit and trainers every day running alongside the children, being that role model. MK Champion, School 5 (TP6)

The distal nature of most of the MK Champions to pupils' participation in MK furthermore meant that there was often a delay in them receiving feedback on their progress and distance covered, if they received any at all. Many pupils described how this compromised their motivation to participate in MK.

We should get like a 'well done' from our teachers. They don't really say anything... I think it would encourage us to keep doing more and more bands. I think that would like encourage us. Year $5 \mathrm{girl}$, School 4 (TP5)

\section{Discussion}

This evaluation was conducted to determine the extent to which a school-based running programme, MK, was implemented. Specifically, it sought to understand the key elements of implementation including reach, fidelity and dose.

Reach

Page $11 / 16$ 
MK appeared to appeal equally to both the active and non-active pupils in the schools; however, boys were more likely to be classified as high participating than girls. This is perhaps not surprising given that pre-programme a higher percentage of boys were meeting the physical activity recommendations, and gender differences in physical activity participation is one of the most pervasive findings in the literature (28). Systematic gender differences in how schoolbased running programmes are received has also recently been reported elsewhere (29). Research further suggests potential differences in how much physical activity children gain from interventions, with a greater tendency for girls to (verbally and physically) interact together while participating (30). This is significant as social factors are powerful motivations for children's participation in physical activity, especially for girls (31) and this seems to be the case here. Previous research posits that physical activity could provide an appropriate context within which to facilitate the development of peer relationships (32) and that friendships are associated with the promotion of self-worth, positive attitudes toward physical activity, and an increased likelihood of continued participation (33). Given the social nature of walking and/or running (with autonomy over how e.g., in pairs and/or groups) and incorporating both participants and MK Ambassadors, MK appears to provide appropriate opportunities for this. It is recommended that schools encourage staff to participate and become role models for the initiative as well as encourage pupils to participate together and facilitate social cohesion.

Fidelity

All schools implemented MK with good fidelity, achieving $75 \%$ or above adherence to the programme's implementation strategies. The qualitative data confirms that this may be attributed to the simple nature of the programme and suggests that it is be easier to achieve good fidelity with simple programmes such as MK, compared to more complex multicomponent programmes which are susceptible to poor fidelity, particularly in real world contexts (11). There is also the added benefit of such programmes requiring very little or no ongoing investment in infrastructure and resources, making it credible for large scale dissemination and adoption (34). Whilst these findings suggest that more could be done to improve the fidelity of MK's implementation, the appropriateness of $100 \%$ fidelity, has been called into question $(35,36)$. Durlak (2015) (35) contend that there may be a minimum threshold for implementation fidelity at which desired programme outcomes are obtained. Indeed, heterogeneity in implementation is expected. This is particularly so within a school setting where adaptation is a necessity for strategies which target one or more levels within the system that supports the adoption and implementation of the intervention (37). Planned adaptations to the implementation of MK were seen in the current study and are recommended (e.g., issuing of rewards and certificates and logging of laps); however, it is important that the underlying features of the programme are maintained (38).

\section{Dose delivered}

Although the programme was delivered with high fidelity, the dose of MK delivered differed considerably between schools. Interestingly, the high frequency of sessions in some schools did not translate to distance accumulated. Recent literature comparing the implementation of a school-based run/walk programme and a classroom-based physical activity break reported that the run/walk programme offered a higher dose of physical activity programming (27). The variation could be partially accounted for by the delivery of MK at different times of the day, and hence the degree of autonomy they allow (16), as well as the variability in influence of the MK Champion. The presence of a champion, (i.e., an individual with sufficient influence and autonomy to galvanise the whole school and secure commitment from staff and pupils), has been demonstrated to be a predictor of school physical activity programme implementation (39) and to influence pupils' participation (16). Indeed, champion-led programmes have advantages with respect to their acceptability, feasibility, and sustainability (40) and it is possible that their involvement, or lack of it, within the participating schools is responsible for some of the effect on dose (delivered and received) within the current study. For meaningful sustained impact, it is recommended that schools recruit a member of the school community who is willing and has capacity to lead the initiative, as a champion.

\section{Dose received}

In all schools a decline in participation in MK was seen after the first couple of weeks suggesting a novelty effect, whereby the programme's perceived newness may have had an initial motivational effect on pupils which was not sustained over time (41). This is consistent with the findings observed in many other school-based interventions (42). Motivational constructs such as enjoyment are believed to be an important determinant of long-term participation (43) and likely to play a more important role in sustaining participation. It is recommended that schools emphasise fun and enjoyment of school-based running programmes and developing a positive experience over and above competition or distance covered. This can be helped by communicating and reinforcing the multiple benefits of participating to pupils, particularly the more immediate short-term benefits (e.g., fun, opportunity to get some fresh air and spend time with friends).

\section{Strengths and limitations}

The strengths of this study included the use of mixed methods, measures at multiple levels (i.e., school and individual) and the collection of these data at multiple time points during implementation and at follow-up, thereby providing a more holistic understanding of the implementation context in a sample of English primary schools.

Whilst the modest sample size may limit the generalisability of the findings, a strength of the study was the recruitment strategy employed to ensure, as far as is possible, representativeness (in terms of size, socioeconomic status and geographic location). Due to financial limitations and the ambition to have equitable representation, the evaluation only focused on one year-group (Year 5). Whilst this may limit the applicability of the findings across the primary school setting more broadly the benefit of using this approach was the ability to examine within-school differences between Year 5 classes within the same school.

\section{Conclusion}


Findings suggest that MK is a simple, yet versatile programme which can be implemented in a variety of school-based environments. The programme had good reach and was delivered with good fidelity, although the dose of MK (delivered and received) fluctuated. Many contextual factors, which differed between schools, influenced the quality of implementation and the frequency of delivery. Whilst this complexity provides challenges, it may also offer opportunities to optimise implementation and inform adaptations specific to the schools' contexts, thereby increasing the likelihood of positive outcomes and programme sustainability.

\section{Abbreviations}

MK: Marathon Kids; UK:United Kingdom; KRF:Kids Run Free; DTS:Digital Tracking System; IDACI:Income of Deprivation Affecting Children Index; TP:Time point; PE:Physical Education; IMD:Index of Multiple Deprivation; eFSM:Free School Meal Eligibility; SD:Standard Deviation; MVPA:Moderate to Vigorous Physical Activity

\section{Declarations}

\section{Ethics approval and consent to participate}

The study has been approved by the Human Participants Ethics Subcommittee of Loughborough University (R16-P116). All participants provided written informed consent and verbal assent prior to participation in any data collection. Parental consent to participate was also obtained from the pupil's parents and carers and each school provided written consent to participate in the study signed by the headteacher.

\section{Consent for publication}

All participants gave permission for their data to be published in an anonymized form.

\section{Availability of data and materials}

The data sets supporting the conclusions of this article are available upon request to the corresponding author.

\section{Competing interests}

None declared

\section{Funding}

This study was funded by London Marathon Events Ltd. and Kids Run Free and supported by the National Institute for Health Research (NIHR) Collaboration for Leadership in Applied Health Research and Care - East Midlands (NIHR CLAHRC - EM) and by the NIHR Leicester Biomedical Research Centre; however, they had no role in the design of the study, collection, analysis, interpretation of data or writing of the manuscript. Consequently, the views expressed are those of the author(s) and not necessarily those of London Marathon Events Ltd., Kids Run Free the NHS, the National Institute for Health Research or the Department of Health

\section{Authors' contributions}

AC and LS initially conceived the original study design. AC collected data and led the analysis. LS and AR independently checked the initial qualitative coding strategies and emerging coding frameworks and LC, JH and TG then served in the capacity of a peer-debriefers. AC conceived and wrote the first draft of the manuscript. All listed authors reviewed and contributed feedback and critical comments on drafts of the manuscript before approving the final version. All authors read and approved the final manuscript.

\section{Acknowledgements}

We are very grateful to the pupils, teachers, headteachers and schools who contributed to this study and Kids Run Free staff who contributed to the formative piece of work that informed the study design as well as the Teaching School Alliance for their support with this research.

\section{References}

1. Sherar, Lauren B, Chalkley AE, Gorely T, Cale LA. School-based running programes. In: Brusseau TA, Fairclough SJ, Lubans DR, editors. The Routledge Handbook of Youth Physical Activity [Internet]. 1st ed. Routledge; 2020. p. 541-56. Available from: https://www.routledge.com/The-Routledge-Handbookof-Youth-Physical-Activity/FAIRCLOUGH-Lubans/p/book/9781138331549

2. National Centre for Sport and Exercise Medicine. Making Strides in Schools symposium report [Internet]. 2016. Available from: http://www.ncsemem.org.uk/making-strides-in-schools/

3. Department of Health. Childhood Obesity: A Plan for Action [Internet]. 2016. Available from: http://content.wkhealth.com/linkback/openurl? sid=WKPTLP:landingpage \&an $=00005721-201601000-00010$

4. The Daily Mile [Internet]. 2013 [cited 2016 Jun 4]. Available from: https://thedailymile.co.uk/

5. Global Map | The Daily Mile UK. 
6. Department for Education, Department for Digital Culture Media and Sport, Department for Health and Social Care. School Sport and Activity Action Plan [Internet]. London; 2019. Available from:

https://assets.publishing.service.gov.uk/government/uploads/system/uploads/attachment_data/file/817093/School_sport_and_activity_action_plan.pdf

7. Dobbins M, DeCorby K, Robeson P, Husson H, Tirilis D, De Corby K. Cochrane review: School-based physical activity programs for promoting physical activity and fitness in children and adolescents aged 6-18. Evidence-Based Child Heal A Cochrane Rev J [Internet]. 2009;4(4):1452-561. Available from: http://www.ncbi.nlm.nih.gov/pubmed/19160341\%5Cnhttp://doi.wiley.com/10.1002/ebch.461

8. Milat AJ, Bauman AE, Redman S, Curac N. Public health research outputs from efficacy to dissemination: A bibliometric analysis. BMC Public Health [Internet]. 2011;11(1):934. Available from: http://www.biomedcentral.com/1471-2458/11/934

9. Jones M, Defever E, Letsinger A, Steele J, Mackintosh KA. A mixed-studies systematic review and meta-analysis of school-based interventions to promote physical activity and/or reduce sedentary time in children. J Sport Heal Sci [Internet]. 2019 Jun;1-15. Available from:

https://linkinghub.elsevier.com/retrieve/pii/S2095254619300808

10. Durlak J a., DuPre EP. Implementation Matters: A Review of Research on the Influence of Implementation on Program Outcomes and the Factors Affecting Implementation. Am J Community Psychol [Internet]. 2008 Jun;41(3-4):327-50. Available from: http://link.springer.com/10.1007/s10464-008-9165-0

11. Love R, Adams J, van Sluijs EMF. Are school-based physical activity interventions effective and equitable? A systematic review and meta-analysis of cluster randomised controlled trials. Lancet [Internet]. 2018;392(November 2018):S53. Available from: https://www.sciencedirect.com/science/article/pii/S0140673618321743

12. Chalkley AE, Routen AC, Harris JP, Cale LA, Gorely T, Sherar LB. Marathon Kids UK: study design and protocol for a mixed methods evaluation of a schoolbased running programme. BMJ Open [Internet]. 2018 May 14;8(5):e022176. Available from: http://bmjopen.bmj.com/lookup/doi/10.1136/bmjopen2018-022176

13. Stylianou M, Kulinna PH, van der Mars H, Mahar MT, Adams MA, Amazeen E. Before-school running/walking club: Effects on student on-task behavior. Prev Med reports [Internet]. 2016 Jun [cited 2017 Jan 5];3:196-202. Available from: http://www.pubmedcentral.nih.gov/articlerender.fcgi? artid $=4929141 \&$ tool $=$ pmcentrez\&rendertype $=$ abstract

14. Public Health England, Loughborough University. Active mile briefing: evidence and policy summary [Internet]. London; 2020. Available from: https://www.gov.uk/government/publications/active-mile-briefings

15. Naylor P, McKay HA. Prevention in the first place: schools a setting for action on physical inactivity. Br J Sports Med [Internet]. 2009 Jan [cited 2016 Nov 20];43(1):10-3. Available from: http://www.ncbi.nlm.nih.gov/pubmed/18971250

16. Chalkley AE, Routen AC, Harris JP, Cale LA, Gorely T, Sherar LB. "I Just Like the Feeling of It, Outside Being Active": Pupils' Experiences of a School-Based Running Program, a Qualitative Study. J Sport Exerc Psychol [Internet]. 2020 Feb 1;42(1):48-58. Available from:

https://journals.humankinetics.com/view/journals/jsep/42/1/article-p48.xml

17. Chalkley AE, Routen AC, Harris JP, Cale LA, Gorely T, Sherar LB. A retrospective qualitative evaluation of barriers and facilitators to the implementation of a school-based running programme. BMC Public Health [Internet]. 2018;18:1189. Available from: https://doi.org/10.1186/s12889-018-6078-1

18. Campbell M, Katikireddi SV, Hoffmann T, Armstrong R, Waters E, Craig P. TIDieR-PHP: A reporting guideline for population health and policy interventions. BMJ. 2018;361:1-5.

19. Miller CJ, Smith SN, Pugatch M. Experimental and quasi-experimental designs in implementation research. Psychiatry Res [Internet]. 2019 Jun;(March):01. Available from: https://doi.org/10.1016/j.psychres.2019.06.027

20. Department for Communities and Local Government. Income of Deprivation Affecting Children Index. London: Department for Communities and Local Government; 2015.

21. Edubase [Internet]. [cited 2016 May 4]. Available from: www.education.gov.uk/edubase/home.xhtml

22. Milton K, Bull FC, Bauman A. Reliability and validity testing of a single-item physical activity measure. Br J Sports Med [Internet]. 2011 Mar 23 [cited 2016 Aug 30];45(3):203-8. Available from: http://bjsm.bmj.com/content/early/2010/07/23/bjsm.2009.068395.full.html

23. Chalkley AE, Routen AC, Harris JP, Cale LA, Gorely T, Sherar LB. Marathon Kids UK: study design and protocol for a mixed methods evaluation of a schoolbased running programme. BMJ Open [Internet]. 2018;8(5):e022176. Available from: http://bmjopen.bmj.com/content/8/5/e022176.abstract

24. Ritchie J, Lewis J. Qualitative Research Practice. London: SAGE Publications; 2003.

25. Ritchie J, Spenser L. Qualitative data analysis for applied policy research. In: Bryman A, Burgess R., editors. Analyzing Qualitative Data. London: Routledge; 1994.

26. Department of Health. Start Active, Stay Active: A report on physical activity from the four home countries' Chief Medical Officers [Internet]. London; 2011. Available from: https://www.gov.uk/government/publications/start-active-stay-active-a-report-on-physical-activity-from-the-four-home-countries-chiefmedical-officers

27. Wright CM, Chomitz VR, Duquesnay PJ, Amin SA, Economos CD, Sacheck JM. The FLEX study school-based physical activity programs - Measurement and evaluation of implementation. BMC Public Health. 2019;19(1):1-12.

28. Pearce MS, Basterfield L, Mann KD, Parkinson KN, Adamson AJ. Early Predictors of Objectively Measured Physical Activity and Sedentary Behaviour in 810 Year Old Children: The Gateshead Millennium Study. Harvey N, editor. PLoS One [Internet]. 2012 Jun 20;7(6):e37975. Available from:

https://dx.plos.org/10.1371/journal.pone.0037975

29. Hanckel B, Ruta D, Scott G, Peacock JL, Green J. The Daily Mile as a public health intervention: a rapid ethnographic assessment of uptake and implementation in South London, UK. BMC Public Health [Internet]. 2019 Dec 27;19(1):1167. Available from:

https://bmcpublichealth.biomedcentral.com/articles/10.1186/s12889-019-7511-9

Page $14 / 16$ 
30. Pawlowski CS, Ergler C, Tjørnhøj-Thomsen T, Schipperijn J, Troelsen J. 'Like a soccer camp for boys.' Eur Phys Educ Rev [Internet]. 2015 Aug 10 [cited 2017 Oct 25];21(3):275-91. Available from: http://journals.sagepub.com/doi/10.1177/1356336X14561533

31. Kopcakova J, Veselska ZD, Geckova AM, Kalman M, van Dijk JP, Reijneveld SA. Do motives to undertake physical activity relate to physical activity in adolescent boys and girls? Int J Environ Res Public Health. 2015;12(7):7656-66.

32. Smith AL. Peer relationships in physical activity contexts: A road less traveled in youth sport and exercise psychology research. Psychol Sport Exerc. 2003;4(1):25-39.

33. Maturo CC, Cunningham SA. Influence of friends on children's physical activity: a review. Am J Public Health [Internet]. 2013 Jul [cited 2017 Jan 23];103(7):e23-38. Available from: http://www.pubmedcentral.nih.gov/articlerender.fcgi?artid=3682627\&tool=pmcentrez\&rendertype=abstract

34. Milat A, Lee K, Conte K, Grunseit A, Wolfenden L, van Nassau F, et al. Intervention Scalability Assessment Tool: A decision support tool for health policy makers and implementers. Heal Res Policy Syst [Internet]. 2020 Dec 3;18(1):1. Available from: https://health-policysystems.biomedcentral.com/articles/10.1186/s12961-019-0494-2

35. Durlak JA. Studying Program Implementation Is Not Easy but It Is Essential. Prev Sci [Internet]. 2015 Nov [cited 2015 Dec 30];16(8):1123-7. Available from: http://www.ncbi.nlm.nih.gov/pubmed/26399607

36. Evans RE, Craig P, Hoddinott P, Littlecott H, Moore L, Murphy S, et al. When and how do 'effective' interventions need to be adapted and/or re-evaluated in new contexts? The need for guidance. J Epidemiol Community Health [Internet]. 2019 Jun;73(6):481-2. Available from: http://jech.bmj.com/lookup/doi/10.1136/jech-2018-210840

37. Kim B, Sullivan JL, Ritchie MJ, Connolly SL, Drummond KL, Miller CJ, et al. Comparing variations in implementation processes and influences across multiple sites: What works, for whom, and how? Psychiatry Res [Internet]. 2019 Aug;(April):112520. Available from:

https://doi.org/10.1016/j.psychres.2019.112520

38. Stirman SW, Miller CJ, Toder K, Calloway A. Development of a framework and coding system for modifications and adaptations of evidence-based interventions. Implement Sci [Internet]. 2013;8(1):1. Available from: Implementation Science

39. Phelps A, Calvert HG, Hwang J, Glowacki E, Carson RL, Castelli D. Environmental Characteristics Related to Comprehensive School Physical Activity Program Implementation. Eur J Environ Public Heal [Internet]. 2018 Sep 28;2(2). Available from: http://www.ejeph.com/article/environmentalcharacteristics-related-to-comprehensive-school-physical-activity-program

40. Franks AL, Kelder SH, Dino GA, Horn KA, Gortmaker SL, Wiecha JL, et al. School-based programs: Lessons learned from CATCH, planet health, and Not-OnTobacco. Prev Chronic Dis. 2007;4(2):1-9.

41. González-Cutre D, Sicilia Á, Sierra AC, Ferriz R, Hagger MS. Understanding the need for novelty from the perspective of self-determination theory. Pers Individ Dif [Internet]. 2016 Nov;102:159-69. Available from: https://linkinghub.elsevier.com/retrieve/pii/S0191886916307863

42. Parrish A-M, Okely AD, Stanley RM, Ridgers ND. The effect of school recess interventions on physical activity: a systematic review. Sports Med [Internet]. 2013 Apr [cited 2015 May 26];43(4):287-99. Available from: http://www.ncbi.nlm.nih.gov/pubmed/23512170

43. Burns RD, Fu Y, Podlog LW. School-based physical activity interventions and physical activity enjoyment: A meta-analysis. Prev Med (Baltim) [Internet]. 2017 Oct [cited 2017 Sep 11];103:84-90. Available from: http://linkinghub.elsevier.com/retrieve/pii/S0091743517302980

\section{Figures}




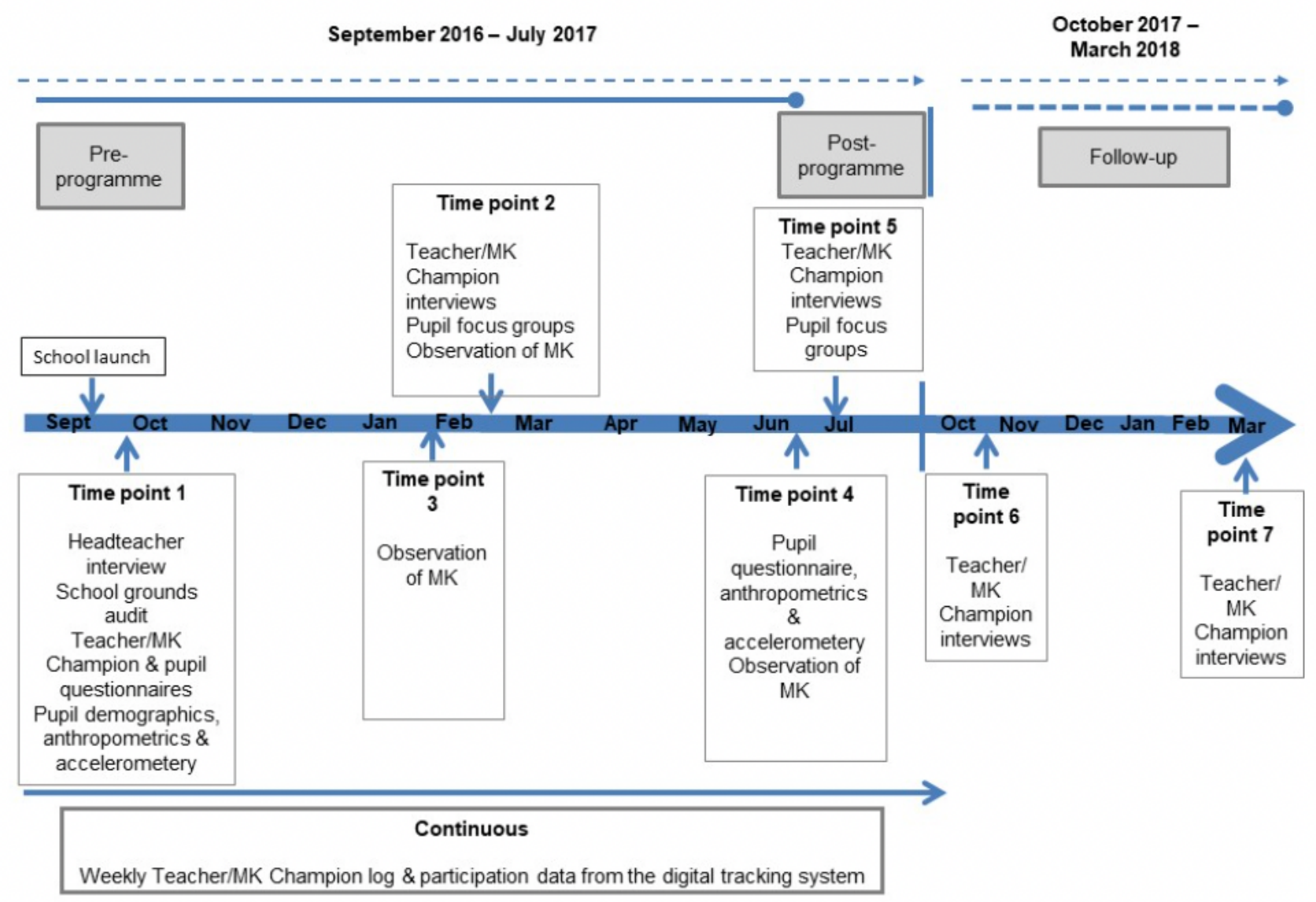

Figure 1

A summary of the evaluation process for Marathon Kids (MK)

\section{Supplementary Files}

This is a list of supplementary files associated with this preprint. Click to download.

- AdditionalFile1TiDieRPHPDescriptionofMK.docx

- AdditionalFile1TiDieRPHPDescriptionofMK.docx

- AdditionalFile2ThematicInterviewandFocusGroupGuide.docx

- AdditionalFile2ThematicInterviewandFocusGroupGuide.docx 